\title{
Modeling the Drilling Process of Aluminum Composites Using Multiple Regression Analysis and Artificial Neural Networks
}

\author{
Ahmad Mayyas ${ }^{*}$, Awni Qasaimeh², Khalid Alzoubi², Susan Lu², Mohammed T. Hayajneh ${ }^{3}$, \\ Adel M. Hassan ${ }^{3}$ \\ ${ }^{1}$ Department of Automotive Engineering, Clemson University International Center for Automotive Research (CU-ICAR), \\ 4 Research Drive, Greenville, USA \\ ${ }^{2}$ System Science and Industrial Engineering, Binghamton University, State University of New York, New York, USA \\ ${ }^{3}$ Industrial Engineering Department, Jordan University of Science and Technology, Irbid, Jordan \\ Email: ${ }^{3}$ ahmadm@g.clemson.edu
}

Received June 18, 2012; revised July 22, 2012; accepted August 4, 2012

\begin{abstract}
In recent years, aluminum-matrix composites (AMCs) have been widely used to replace cast iron in aerospace and automotive industries. Machining of these composite materials requires better understanding of cutting processes regarding accuracy and efficiency. This study addresses the modeling of the machinability of self-lubricated aluminum /alumina/graphite hybrid composites synthesized by the powder metallurgy method. In this study, multiple regression analysis (MRA) and artificial neural networks (ANN) were used to investigate the influence of some parameters on the thrust force and torque in the drilling processes of self-lubricated hybrid composite materials. The models were identified by using cutting speed, feed, and volume fraction of the reinforcement particles as input data and the thrust force and torque as the output data. A comparison between two prediction methods was developed to compare the prediction accuracy. ANNs showed better predictability results compared to MRA due to the nonlinearity nature of ANNs. The statistical analysis accompanied with artificial neural network results showed that $\mathrm{Al}_{2} \mathrm{O}_{3}$, Gr and cutting feed $(f)$ were the most significant parameters on the drilling process, while spindle speed seemed insignificant. Since the spindle speed was insignificant, it directed us to set it either at the highest spindle speed to obtain high material removal rate or at the lowest spindle speed to prolong the tool life depending on the need for the application.
\end{abstract}

Keywords: Artificial Neural Network; Metal-Matrix Composites (MMCs); Multiple Regression Analysis; Statistical Methods; Machining

\section{Introduction}

Metal-matrix composites (MMCs) form a group of engineered materials that have received considerable research. The most popular reinforcements are silicon carbide, alumina and graphite. Aluminum, titanium and magnesium alloys are commonly used as the matrix phase. According to many authors metal-matrix composites (MMCs) have many advantages over monolithic materials, including higher specific strength, higher thermal conductivity than ceramic materials, good wear resistance, lower coefficient of thermal expansion [1-5]. MMCs compete with super-alloys, ceramics plastics and redesigned steel parts in several aerospace and automotive applications. Therefore, the development of composite materials has been an area of intensive interest for the past 30 years. The object for producing composite mate-

\footnotetext{
"Corresponding author.
}

rials is to achieve a spectrum of properties that cannot be obtained in any of the constituent materials acting alone.

Efforts have been made to develop near net shape manufacturing for these products, but some amount of finishing needs to be done in order to complete the assembly process. However, for assembly and joining, secondary machining processes such as drilling are required. Drilling is often the last manufacturing process to be performed on a part before assembly [6].

However, because of the poor machining properties of metal-matrix composites (MMCs), drilling of MMCs is a challenging task for manufacturing engineers. Unlike machining of conventional materials, many problems are present during drilling of MMCs, such as tool wear, high drilling forces, and burrs height [7]. Aluminum is commonly machined with high speed steel, diamond and carbide tooling. However, silicon nitride-based ceramic tools are generally not used in aluminum because of the 
high solubility of silicon in aluminum [8]. Cutting forces are generally low and, because aluminum is a good conductor of heat, and since most aluminum alloys melt at temperatures between $500^{\circ} \mathrm{C}$ and $600^{\circ} \mathrm{C}$, cutting temperatures and tool wear rates are also low [7,8]. When cut under proper conditions with sharp tools, aluminum alloys acquire fine finishes through turning, drilling and milling, minimizing the necessity for grinding and polishing operations. The major machinability concern with aluminum alloys includes tool life, chip characteristics, chip disposal and surface finish $[9,10]$. However, dry machining is now considered for two major reasons: 1) The potential reduction in cost by minimizing or eliminating the use of cutting fluids, which are expensive to use and maintain. 2) The health and environmental benefits of minimizing metalworking fluid use, termed "green machining" [11,12]. Dry machining of aluminum alloys provides a significant cost savings, including the costs associated with purchasing metalworking fluids and biocides added to minimize microbial growth, maintaining equipment used to deliver metalworking fluids to the work surface, and ultimate disposal [8].

Statistical methods are now using significantly in the area of composite materials $[1,13]$. For example Taguchi method was used for modeling the drilling process of aluminum matrix composite materials using the (A356/ 20/ $\mathrm{SiC}_{\mathrm{P}}$-T6: aluminum with $7.0 \%$ silicon, $0.4 \%$ magnesium, reinforced with $20 \%$ vol. $\%$ particles of silicon carbide [SiC]- heat treatment (solutionising and aging T6-5 $\mathrm{h}$ at $154^{\circ} \mathrm{C}$ ) [1]. The objective was to establish correlation between cutting velocity, feed rate and cutting time using multiple regression analysis. The evaluated responses were tool wear, specific cutting pressure and holes' surface roughness. In this study many empirical correlations were established and used to predict the outputs based on a given range of inputs.

The use of regression analysis (RA) and artificial neural networks (ANNs) represents a new methodology in many different applications of composite materials including prediction of mechanical properties of aluminum based materials [13-15]. They are promising fields of research in predicting experimental trends and have become increasingly popular in the last few years. They can often solve problems much faster compared to other approaches with the additional ability to learn from small experimental data, especially for ANN. Artificial neural networks were used to predict some mechanical properties of $\mathrm{Al}-\mathrm{Mg}-\mathrm{Cu} / \mathrm{SiC}$ composite materials $[5,14]$. It was found that ANN has the ability to predict mechanical properties accurately and efficiently, hence reducing experimental time and cost. Also, ANN was used to predict the effect of thermo-mechanical parameters on mechanical properties of aluminum alloy AA3004 [15]. By using a well-trained ANN models a reliable and accurate re- sults could be obtained. ANNs provide fast, accurate and consistent results, making them superior to all other techniques ANN. Moreover, ANN and multiple regression methods in analyzing machining parameters of aluminum alloy reinforced with silicon carbide particles with attention on tool wear [13]. Also it was found that ANN has the ability to predict tool wear accurately from feed force. Another advantage of using ANNs in engineering materials is to model tribological behaviors of short alumina fiber reinforced zinc-aluminum composites [16]. In this study, the specific wear rate and coefficient of friction obtained from a series of the wear tests were used in the formation of training sets of ANN. Again, ANN was proved to be an excellent prediction technique in such area if it is well trained.

Selection of machinability data, which includes choosing the appropriate machining parameters, plays an important role in the efficient operation of machine tools and thus considerably influences the overall manufacturing costs. The cutting process is very complex. Knowledge about the machining process is limited. The uncertainty and incomplete knowledge are inherent to machine tools. The cutting process is subject to large disturbances because of variations in machinability, raw materials and the machining conditions. There has been little work related to the modeling of the drilling process. The goal of this paper is not to focus on the analysis of these models as the analytical standard models have not introduced good results in practice. Accordingly, an alternative to these models is the neural network model. There are a series of reasons that justify the use of neural network in the modeling of complex cutting processes [5,13,14]. Probably the most important is its ability to cope with uncertainty and imprecision, which are always present in systems with well-defined complexity, where the relationships between the variables are unknown [13]. Therefore, the main objective of this study is to provide a method of prediction of the main parameters for metal cutting processes of $\mathrm{Al}_{-}-\mathrm{Al}_{2} \mathrm{O}_{3}-\mathrm{Gr}$ composites.

This study is an attempt to develop prediction models for the drilling process of aluminum- based composite materials to help the selection of cutting parameters and the improvement of the drilling process. In the present work, multiple regression analysis (MRA) and artificial neural network (ANN) models were used to investigate the influence of some parameters on the thrust force and torque in the drilling processes. The model for the cutting forces is identified by using cutting speed, feed, and volume fraction of the reinforced particles as input data and the thrust force and torque as the output data.

\section{Multiple Regression Analysis}

Regression analysis is a statistical tool for the investigation of relationships between variables. Usually, the in- 
vestigator seeks to ascertain the causal effect of one variable upon another. Multiple regression analysis (MRA) is widely used to model the cause and effect relationship between inputs and outputs and can be generally expressed as [17]:

$$
Y=f\left(X_{1}, X_{2}, \cdots, X_{n} ; \theta_{1}, \theta_{2}, \cdots, \theta_{n}\right)+\varepsilon
$$

where $Y$ is a dependent variable (i.e. output variable), $X_{1}, \cdots, X_{n}$ are independent or explanatory variables (i.e. input variables), $\theta_{1}-\theta_{p}$ are regression parameters, $\varepsilon$ is a random error, which is assumed to be normally distributed with zero mean and constant variance $\sigma^{2}$, and $f$ is a known function, which may be linear or nonlinear. If $f$ is linear, then Equation (1) becomes a multiple linear regression model which can be expressed as [17]:

$$
Y=b_{0}+b_{1} X_{1}+b_{2} X_{2}+\cdots b_{n} X_{n}+\varepsilon
$$

where $b_{0}$ is a constant and called intercept. Different functional forms decide different MRA models.

Estimation of the regression parameters $\theta_{1}-\theta_{p}$ or $\mathrm{b}_{0}-$ $b_{n}$ is made using least squares method (LSM). LSM can be expressed as an unconstrained optimization problem:

$$
\begin{aligned}
& \text { Minimize } \\
& J=\sum_{t=1}^{T} Y_{\mathrm{t}}-f\left(X_{1 t}, X_{2 t}, \cdots, X_{n t} ; \theta_{1}, \theta_{2}, \ldots . \theta_{p}\right)^{2}
\end{aligned}
$$

where $t=1, \cdots, T$ represent $T$ different sample points.

However, the corresponding regression model can be utilized for prediction if the regression parameters are determined.

Another important prediction measure is the coefficient of determination $\mathrm{R}^{2}$. Coefficient of determination measures the amount of variation in the dependent variables. The closer this is to 1 the better. Since $\mathrm{R}^{2}$ can be made larger simply by adding more predictor variables to the model. To overcome this $\mathrm{R}^{2}$-adj is widely used in association with $\mathrm{R}^{2}$. This adjusted $\mathrm{R}^{2}$ does not automatically increase when new predictor variables are added to the model. In fact, the adjusted $\mathrm{R}^{2}$ may actually decrease, because the decrease in SSE may be more than offset by the corresponding decrease in the error degree of freedom (df). $\mathrm{R}^{2}$ and $\mathrm{R}^{2}$-adj can be expressed as follow [17]:

$$
\begin{aligned}
& \mathrm{R}^{2}=\frac{\mathrm{SSR}}{\mathrm{SST}}=1-\frac{\mathrm{SSE}}{\mathrm{SST}} \\
& \mathrm{R}_{\text {adj }}^{2}=1-\frac{\mathrm{SSE} / \mathrm{dfE}}{\mathrm{SST} / \mathrm{dfT}}=1-\frac{\mathrm{MSE}}{\mathrm{MST}}
\end{aligned}
$$

where SSR: regression sum of squares, SSE: error sum of squares, SST: total sum of squares, MSE: errors mean square, and MST: total mean square.).

\section{Artificial Neural Networks (ANNs)}

Artificial neural networks (ANNs) are considered as arti- ficial intelligence modeling techniques. They have highly interconnected structures similar to the brain cells of human neural networks and consist of a large number of simple processing elements called neurons, which are arranged in different layers in the network. Artificial neural networks are considered massive parallel distributed processors made up of simple processing units, which have a natural propensity for storing experimental know ledge and making it available for use. It resembles the brain in two respects: 1) Knowledge is acquired by the network from its environment through a learning process, and 2) Interconnection weights are used to store the acquired knowledge.

\subsection{Learning Algorithm}

Each network consists of an input layer, an output layer and one or more hidden layers. One of the well-known advantages of ANN is that the ANN has the ability to learn from the sample set, which is called a training set, in a supervised or unsupervised learning process. Once the architecture of the network is defined, then, through a learning process, weights are calculated so as to present the desired output [18-20]. Figure 1 shows a traditional algorithm used for training feed forward back propagation neural network.

Artificial neural networks are adaptive statistical devices. This means that they can change the values of their parameters (i.e. the weights) as a function of their performance. These changes are made according to learning rules, which can be characterized as supervised (when a desired output is known and used to compute an error

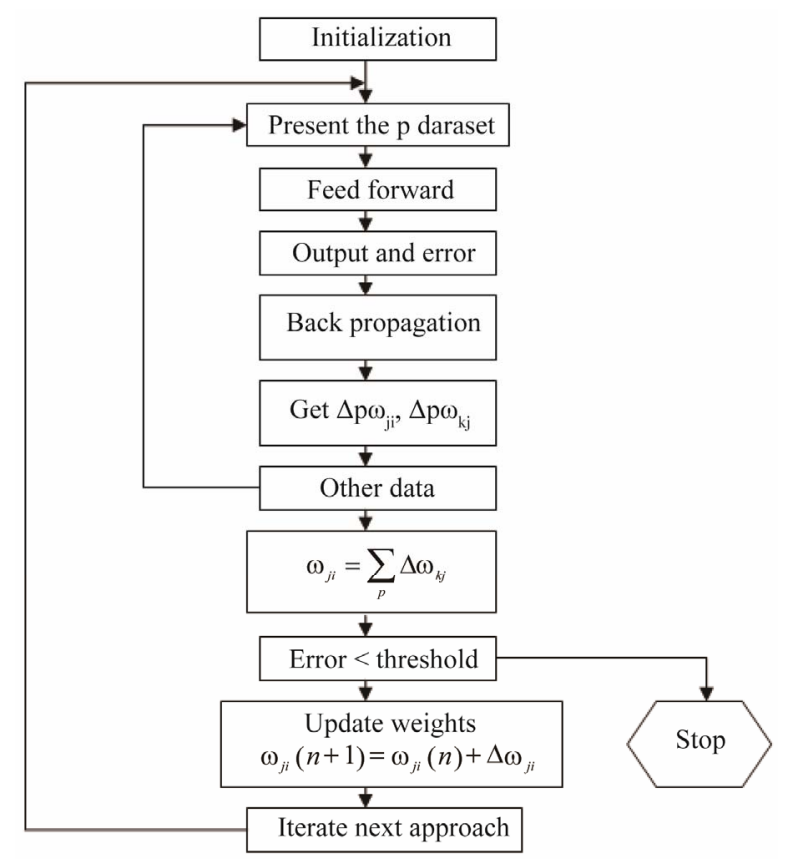

Figure 1. Traditional ANN training algorithm [21]. 
signal) or unsupervised (when no such error signal is used). There are many activation functions used in training algorithms of ANN. Linear and Sigmoid activation functions are widely used among others. Sigmoid function is the most common activation function in ANN because it combines nearly linear behavior, curvilinear behavior, and nearly constant behavior, depending on the value of the input. The sigmoid function is sometimes called a squashing function, since it takes any real-valued input and returns an output bounded between $[0,1]$ $[18,19]$.

$$
y=f(x)=\frac{1}{1+e^{-\mathrm{net}}}
$$

The backpropagation neural network is a multiple layer ANN with one input layer, one output layer and some hidden layers between the input and output layers. Its learning procedure is based on the gradient search with least mean squared optimality criteria. Once the input data are fed to the nodes in the input layer $\left(o_{i}\right)$, this will be fed to nodes $(j)$ in the hidden layer through weighting factors $\left(w_{j i}\right)$, the details are given below.

The net input to node $j$ can be represented as:

$$
\text { net }_{j}=\sum_{i} w_{j i} o_{i}-b_{i}
$$

where $b_{j}$ is the bias over node $j$ and the output of the node $j$ can be expressed using sigmoid activation function as:

$$
o_{i}=\frac{1}{1+e^{- \text {net }_{j}}}
$$

If linear activation function was used then it can be expressed as:

$$
o_{i}=a+b x
$$

Similarly, the outputs from nodes in the hidden layer are fed into nodes in the output layer. This process is called the feed forward stage. After the feed forward stage is done, output $\left(o_{p k}\right)$ can be obtained from nodes in the output layer. In general, the output $o_{p k}$ will not be the same as the desired known target $t_{p k}$. Therefore, the average system error can be calculated as:

$$
E=\frac{1}{2 p} \sum_{p} \sum_{k}\left(t_{p k}-o_{p k}\right)^{2}
$$

The error is then backpropagated from output layer nodes into hidden layer nodes using gradient descent method.

$$
\Delta_{p} w_{k i}=-\eta \frac{\partial E}{w_{k i}}=\eta \delta_{k} O_{j}
$$

The $\delta$ value for output layer is given by

$$
\delta_{k}=o_{k}\left(1-o_{k}\right)\left(t_{k}-o_{k}\right)
$$

This process is called backpropagation stage. After all examples are trained, the system will collect adjusted weights according to:

$$
\Delta w_{j i}=\sum_{p} w_{j i}
$$

The updating of weights will be done according to:

$$
w_{j i}(n+1)=w_{j i}(n)+\Delta w_{j i}
$$

Backpropagation neural networks represent a supervised learning method, requiring a large set of complete records, including the target variables. As each observation from the training set is processed through the network, an output value is produced from output nodes. These values are then compared to the actual values of the target variables for this training set observation and the errors (actual-output) are calculated. Mean square error value (MSE) was used to evaluate the training performance of the ANN.

\section{Materials and Methods}

\subsection{Materials}

Aluminum, $\left(\mathrm{Al}_{2} \mathrm{O}_{3}\right)$ and graphite $(\mathrm{Gr})$ powders of different sizes were mixed thoroughly. The chemical composition of the aluminum powder is shown in Table 1. The specifications of the powders used to prepare the specimens are shown in Table 2.

Typical powder metallurgy technique was followed in this study [22-24]. Specific amount of alumina $\left(\mathrm{Al}_{2} \mathrm{O}_{3}\right)$ and graphite $(\mathrm{Gr})$ particles were added to the aluminum powder. Alumina and graphite were added in three different levels: 0,2 or 4 vol\%. Powders were mechanically blended in a mixer for $2 \mathrm{~h}$ at $90 \mathrm{rpm}$. Then the premixes were compacted using precision metal die with Ø $25 \mathrm{~mm}$ in the laboratory vertical unidirectional press with a capacity of $150 \mathrm{MPa}$ to yield the green compacts. The green compacts were put inside a special sintering die (Figure 2) during the sintering process in order to prevent the possible distortion at high sintering temperature. The sintering profile is shown in Figure 2. This process metallurgically bonds the powder particles together and develops the desired physical and mechanical properties.

\subsection{Drilling Process}

Drilling operations were conducted on "Q\&S Drill master (QSE3)" drilling machine using standard $5 \mathrm{~mm}$ diameter solid carbide twist drills (R415.5-0500-30-8C0). The parameters included: three alumina, $\mathrm{Al}_{2} \mathrm{O}_{3}$, particles contents ( 0 vol.\%, 2 vol.\%, 4 vol.\%), three graphite, Gr, particles contents ( 0 vol.\%, 2 vol.\%, 4 vol.\%), three cutting feeds, F, $(0.076,0.127$ and $0.152 \mathrm{~mm} / \mathrm{rev})$ and three spindle speeds, $\mathrm{N},(150,300$, and $600 \mathrm{rpm})$. To ensure reliable and accurate results the drills used to execute the experiment were selected randomly. The experiment setup is shown in Figure 3. 
Table 1. Chemical composition of the aluminum powder.

\begin{tabular}{cccccc}
\hline $\mathbf{F e}$ & $\mathbf{S i}$ & $\mathbf{C u}$ & $\mathbf{M n}$ & $\mathbf{Z n}$ & Al \\
\hline 0.09 & 0.05 & 0.0005 & 0.001 & 0.031 & Balance \\
\hline
\end{tabular}

Table 2. Specifications of different powders used in this study.

\begin{tabular}{ccc}
\hline Powder & Particle size & Particle shape \\
\hline Aluminum & $1-10 \mu \mathrm{m}$ & Random \\
Graphite & $0.7-5 \mu \mathrm{m}$ & Flakes \\
Alumina & $24-240$ mesh & Irregular \\
\hline
\end{tabular}

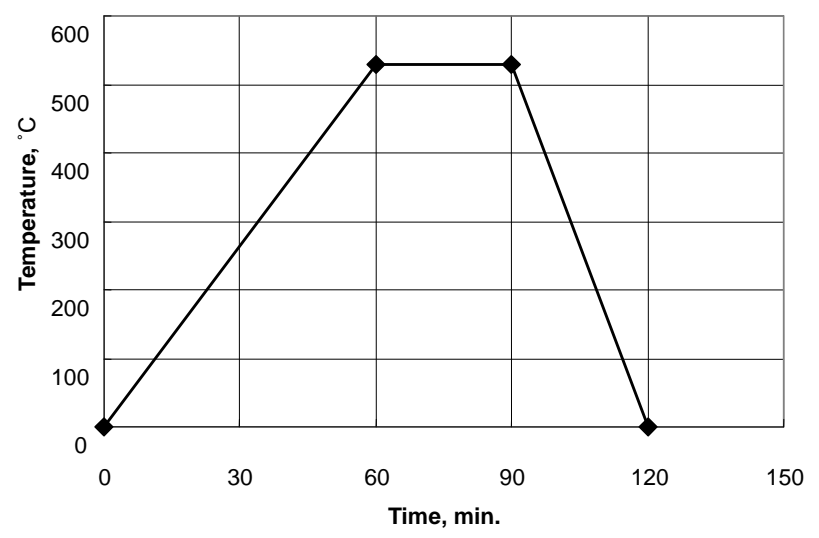

Figure 2. Sintering profile.

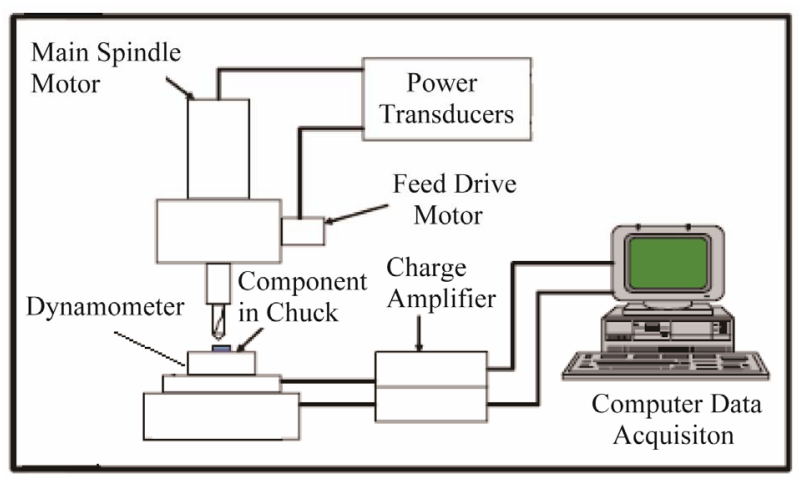

Figure 3. Equipment setup and data acquisition system on the vertical machining center.

\subsection{Measurement of Thrust Force and Torque}

Figure 4 shows a sample graph of the measurement of thrust force and cutting torque. Two-component drill dynamometer (BKM 2000 TeLC drilling dynamometer) has been used to measure the thrust force and cutting torque during the drilling process. XKM 2000 software was used for the data acquisition of $\mathrm{TeLC}^{\circ}$ cutting tool dynamometers with serial data interface to $\mathrm{PC}$ computer.

\section{Results and Discussion}

Experiments have been performed in order to investigate

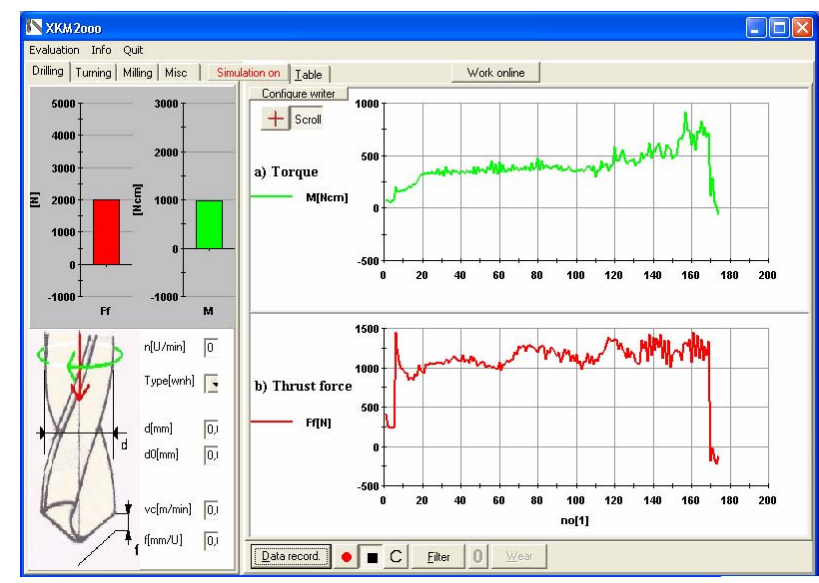

Figure 4. Sample graph of machinability charts: (a) torque; and (b) thrust force.

the effects of one or more factors, i.e. cutting speed, feed, and volume fraction of the reinforced particles on the thrust force and torque during drilling process of the considered composite. When an experiment involves two or more factors, the factors can affect the response individually or interactively. Generally, the experimental design does not give an idea about the interaction effects of the factors as in the case of one-factor-at-a-time experimentation. All possible factor level combination experiments conducted in completely randomized designs are especially useful for testing the interaction effect of the factors. Completely randomized designs are appropriate when there are no restrictions on the order of the testing to avoid systematic biases.

\subsection{Multiple Regression Analysis Results}

To establish the prediction model, a software package MINITAB 15 was used to perform the multiple regression analysis using the above experiment data.

The first step in regression analysis was developing linear regression models and examining their prediction accuracy. Tables $\mathbf{3}$ and $\mathbf{4}$ show the linear regression models for thrust force and torque, respectively. The linear regression model works well in thrust force analysis with $\mathrm{R}^{2}=92.6 \%$ and $\mathrm{R}^{2}(\operatorname{adj})=92.2 \%$. Its prediction ability for torque model seems inefficient with $\mathrm{R}^{2}=77.8 \%$ and $\mathrm{R}^{2}(\operatorname{adj})=76.6 \%$. This shortcoming leads us to transform the outputs into logarithmic scale prior to use linear regression model. This is also to eliminate the inequality of the residuals variance with respect to time as shown in Figures 5-8 (Montgomery and Runger 2003). Figures 5 and $\mathbf{6}$ show normal probability plots for residuals for $\ln$ (torque) and $\ln$ (thrust force), respectively, and Figures $\mathbf{7}$ and $\mathbf{8}$ show plots of residuals versus predicted values for $\ln$ (torque) and $\ln$ (thrust force), respectively. The usual diagnostic checks were applied to the residuals for thrust force and torque regression models. Normal prob- 
Table 3. Linear regression model for thrust force.

Thrust force $(\mathrm{N})=-17.6+22.4 \mathrm{Al}_{2} \mathrm{O}_{3}(\mathrm{vol} \%)-15.2 \mathrm{Gr}(\mathrm{vol} \%)+$ 1371 Cutting feed $(\mathrm{mm} / \mathrm{rev})+0.0146$ Spindle speed $(\mathrm{rpm})$

\begin{tabular}{ccccc}
\hline Predictor & Coefficient & SE Coef & $\mathrm{T}$ & $p$-value \\
\hline Constant & -17.598 & 9.257 & -1.90 & 0.061 \\
$\mathrm{Al}_{2} \mathrm{O}_{3}($ vol\%) & 22.412 & 1.235 & 18.15 & 0.000 \\
$\mathrm{Gr}($ vol\%) & -15.206 & 1.235 & -12.31 & 0.000 \\
Cutting feed & 1371.35 & 63.77 & 21.50 & 0.000 \\
Spindle speed & 0.014615 & 0.009628 & 1.52 & 0.133 \\
$\mathrm{~S}=18.1526, \mathrm{R}-\mathrm{Sq}=92.6 \%, \mathrm{R}-\mathrm{Sq}(\mathrm{adj})=92.2 \%$ & & \\
\hline
\end{tabular}

Table 4. Linear regression model for torque.

Torque $(\mathrm{N} . \mathrm{cm})=-7.81+8.07 \mathrm{Al}_{2} \mathrm{O}_{3}(\mathrm{vol} \%)-4.72 \mathrm{Gr}(\mathrm{vol} \%)+$ 185 Cutting feed $(\mathrm{mm} / \mathrm{rev})+0.00396$ Spindle speed $(\mathrm{rpm})$

\begin{tabular}{ccccc}
\hline Predictor & Coefficient & SE Coef & $\mathrm{T}$ & $p$-value \\
\hline Constant & -7.815 & 4.606 & -1.70 & 0.094 \\
$\mathrm{Al}_{2} \mathrm{O}_{3}(\mathrm{vol} \%)$ & 8.0731 & 0.6146 & 13.13 & 0.000 \\
$\mathrm{Gr}(\mathrm{vol} \%)$ & -4.7185 & 0.6146 & -7.68 & 0.000 \\
Cutting feed & 184.84 & 31.74 & 5.82 & 0.000 \\
Spindle speed & 0.003955 & 0.004791 & 0.83 & 0.412 \\
$\mathrm{~S}=9.03345, \mathrm{R}-\mathrm{Sq}=77.8 \%, \mathrm{R}-\mathrm{Sq}(\mathrm{adj})=76.6 \%$ & & \\
\hline \multicolumn{5}{r}{}
\end{tabular}

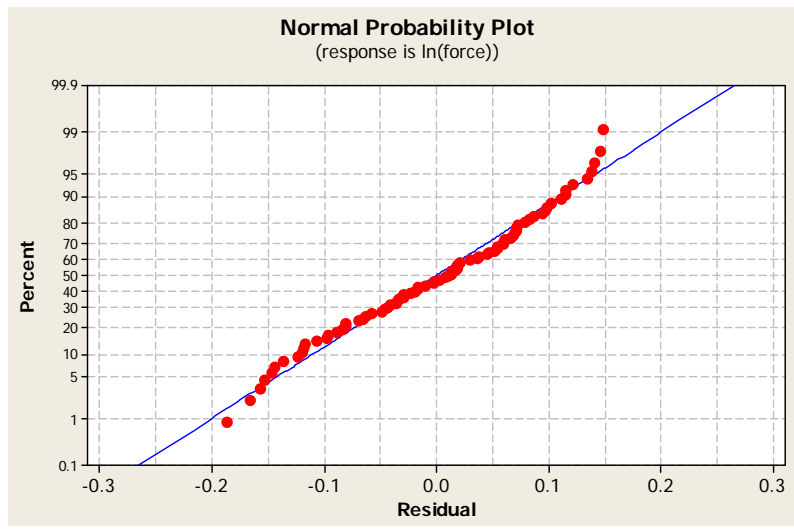

Figure 5. Normal probability plot of $\ln ($ thrust force).

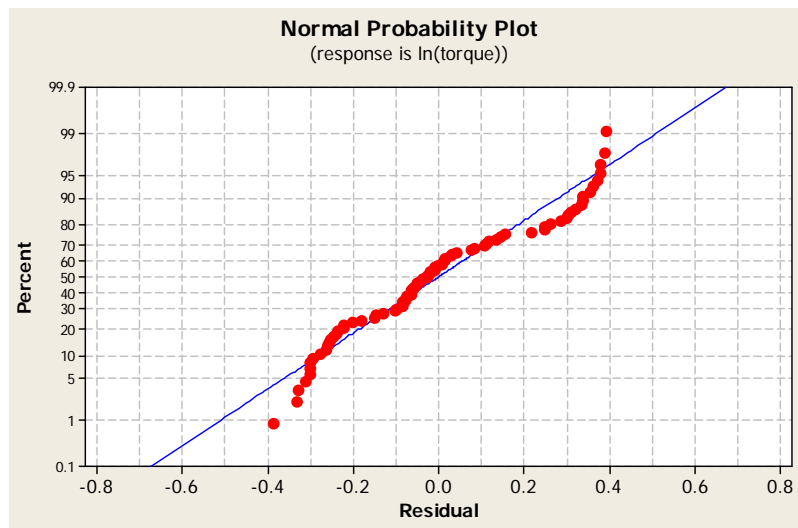

Figure 6. Normal probability plot of $\ln ($ torque).

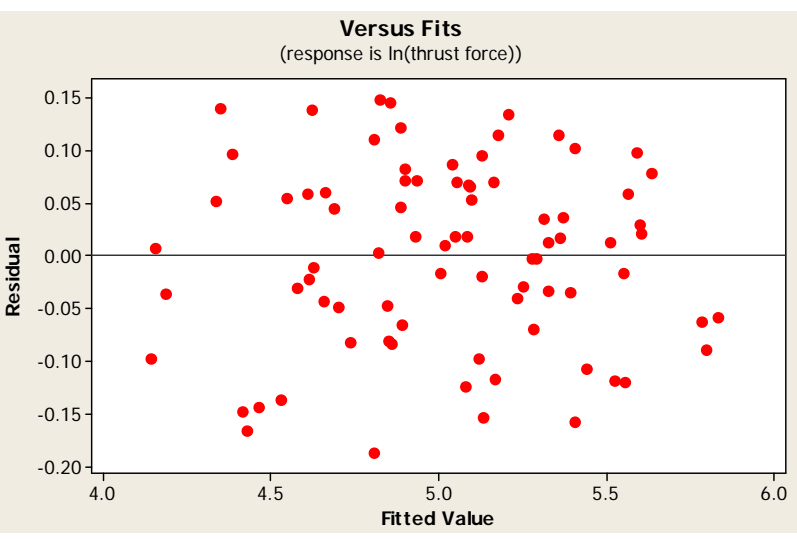

Figure 7. Residual plot of the $\ln ($ thrust force) versus predicted values.

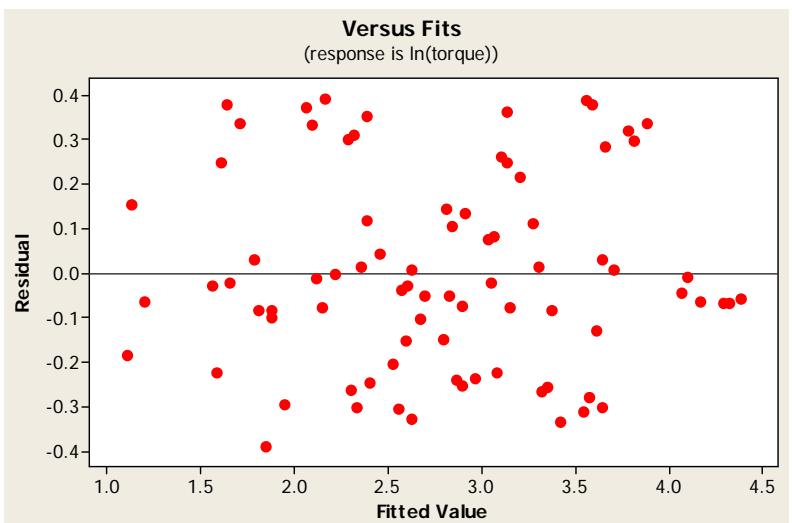

Figure 8. Residual plot of the $\ln ($ torque) versus predicted values.

ability plots ,especially for the torque model, have intervals (especially tails) that do not fall exactly along the straight line passing through the center, which indicating some potential problems with the normality assumption, but the deviation from normality does not appear sever. Moreover, residual plots do not show any pattern or trend of the residuals which means good normality assumption for both models (Figures 7 and 8 ).

Linear regression models are shown in Tables 5 and $\mathbf{6}$ for $\ln$ (thrust force) and $\ln$ (torque), respectively. In these models higher values of both $\mathrm{R}^{2}$ and $\mathrm{R}^{2}$ (adj) were obtained. $\mathrm{R}^{2}$-adj $=95.46 \%$ and $\mathrm{R}^{2}$-adj $=92.65 \% \%$ for $\ln$ (thrust force) and $\ln ($ torque $)$, respectively. It is worth to mention that $\mathrm{R}^{2}$ and $\mathrm{R}^{2}$-adj do not ensure good prediction model, these values should be used as indication of goodness of fit, but with caution [17].

$p$-values were close to zero in the analysis of variance (ANOVA) as presented in Tables 5 and $\mathbf{6}$ indicating satisfactory goodness of fit for these models. Among the four parameters considered in analysis of $\ln$ (thrust force), $\mathrm{Al}_{2} \mathrm{O}_{3}$ (vol\%), $\mathrm{Gr}$ (vol\%) and cutting feed significantly affect the thrust force independently for a significance level $\alpha=0.05$ as shown in Table 5. However, spindle 
Table 5. Linear regression model for $\ln ($ thrust force).

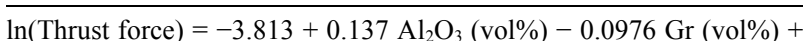
9.262 Cutting feed $(\mathrm{mm} / \mathrm{rev})+0.0001$ Spindle speed $(\mathrm{rpm})$

\begin{tabular}{ccccc}
\hline Term & Coef. & SE Coef & $\mathrm{T}$ & $p$-value \\
\hline Constant & 3.81253 & 0.04494 & 84.846 & 0.000 \\
$\mathrm{Al}_{2} \mathrm{O}_{3}$ & 0.13704 & 0.00600 & 22.857 & 0.000 \\
$\mathrm{Gr}$ & -0.09758 & 0.00600 & -16.275 & 0.000 \\
Cutting feed & 9.26208 & 0.30958 & 29.918 & 0.000 \\
Spindle speed & 0.00009 & 0.00005 & 2.017 & 0.047 \\
$\mathrm{~S}=0.0881180 ; \mathrm{R}-\mathrm{Sq}=95.69 \% ; \mathrm{R}-\mathrm{Sq}(\mathrm{adj})=95.46 \%$ & \\
\hline
\end{tabular}

Table 6. Linear regression model for $\ln ($ torque).

$\ln ($ Torque $)=1.408+0.374 \mathrm{Al}_{2} \mathrm{O}_{3}($ vol $\%)-0.254 \mathrm{Gr}($ vol $\%)+8.933$ Cutting feed $(\mathrm{mm} / \mathrm{rev})+0.0002$ Spindle speed $(\mathrm{rpm})$

\begin{tabular}{ccccc}
\hline Term & Coef & SE Coef & $\mathrm{T}$ & $p$-value \\
\hline Constant & 1.40802 & 0.114153 & 12.334 & 0.000 \\
$\mathrm{Al}_{2} \mathrm{O}_{3}$ & 0.37386 & 0.015232 & 24.545 & 0.000 \\
$\mathrm{Gr}$ & -0.25409 & 0.015232 & -16.682 & 0.000 \\
Cutting feed & 8.93298 & 0.786467 & 11.358 & 0.000 \\
Spindle speed & 0.00019 & 0.000119 & 1.616 & 0.110 \\
$\mathrm{~S}=0.223857 ; \mathrm{R}-\mathrm{Sq}=93.02 \% ; \mathrm{R}-\mathrm{Sq}(\mathrm{adj})=92.65 \%$ & \\
\hline
\end{tabular}

speed is considered marginal, but still important in this model with $p$-value less than 0.05 . The final regression model is:

$$
\begin{aligned}
\ln \left(F_{t h}\right) & =-3.813+0.137 X_{1}-0.0976 X_{2} \\
& +9.262 X_{3}+0.0001 X_{4}
\end{aligned}
$$

where $F_{t h}$ represents thrust force, $X_{1}$ represents $\mathrm{Al}_{2} \mathrm{O}_{3}$ (vol\%), $X_{2}$ represents $\mathrm{Gr}(\mathrm{vol} \%)$, and $X_{3}$ represents cutting feed and $X_{4}$ represents spindle speed.

Similarly for (ln(torque)) model, the final regression model is:

$$
\ln (\text { Torque })=1.408+0.374 X_{1}-0.254 X_{2}+8.933 X_{3}
$$

where $X_{1}$ represents $\mathrm{Al}_{2} \mathrm{O}_{3}$ (vol\%), $X_{2}$ represents $\mathrm{Gr}$ (vol\%), $X_{3}$ represents cutting feed $(\mathrm{mm} / \mathrm{rev})$, and $X_{4}$ represents spindle speed (rpm).

The signs of the parameters in the model presented in Tables 5 and 6 were examined. Positive signs mean the response output (either thrust force or torque) values go in the same direction as the parameter, and negative signs imply the opposite.

To test the prediction performance of the $\ln$ (thrust force) and $\ln ($ torque) regression models, the absolute relative errors were computed based on experimental and predicted values. The absolute relative error (ARE) was computed based on the following equation:

$$
\operatorname{ARE}(\%)=\frac{\mid \text { Predicted value }- \text { Experimental value } \mid}{\text { Experimental value }}
$$

Average absolute relative errors (ARE) were $12.59 \%$ and $7.10 \%$ for $\ln$ (thrust force) and $\ln$ (torque), respectively. Although these error levels could be accepted in some cases, better prediction models may give better predictability and lower error values. This leads us to use ANN for prediction purposes instead of MRA because it performs well and gives a better mapping between inputs and outputs.

\subsection{Artificial Neural Network Results}

The ANN was implemented using fully developed feed forward backpropagation network. The models for cutting forces are identified by using the alumina $\left(\mathrm{Al}_{2} \mathrm{O}_{3}\right)$ particles contents, graphite $(\mathrm{Gr})$ particles contents, cutting feeds $(f)$ and spindle speeds (N) as input data and thrust force and cutting torque as the output data. An 4-10-2 ANN topology was used, which consists of four input nodes, one hidden layer (10 neurons in the) and two outputs (thrust force and torque).

The inputs in ANN nodes must be a numerical value and fall in the closed interval $[0,1]$. The input data were normalized $\mathrm{n}$ the range between 0 and 1 using the following formula:

$$
\begin{aligned}
& \text { Normalized value } \\
& =\frac{\text { input value }- \text { minimum value }}{\text { maximum value }- \text { minimum value }}
\end{aligned}
$$

Output values resulting from ANN were also in the range $[0,1]$ and converted to their equivalent values based on reverse method of normalization technique.

All of the original 81 machining conditions were randomly divided into three datasets including a training, validation and testing datasets. The training set contained $57(70 \%)$ data points were used to build the network, 12 data points $(15 \%)$ were used to measure network generalization and another 12 points (15\%) were used as a testing set of the neural network. Sigmoid activation function was selected to be the transfer function in the hidden layer and linear function was used between hidden layer and output layer (Figure 9). After many trials, learning rate and momentum were experimentally selected to be 0.03 and 0.9 , respectively. LevenbergMarquardt training algorithm was used to train this ANN. Training, testing and validation process were terminated after 106 cycles and further iterations had insignificant effect on error reduction. The obtained MSE value was 0.00182 . Hence, one can conclude that a simple architecture can be used efficiently without loss of prediction accuracy. Table 7 summarizes ANN training and validation parameters as well final training error.

However, the main quality indicator of a neural network is its generalization ability, in other words, its ability to predict accurately the output of unseen data; this was achieved by testing dataset. Absolute relative errors 


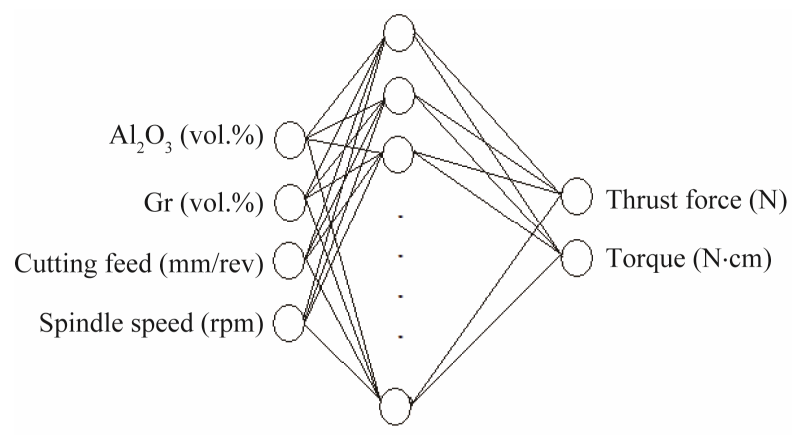

Figure 9. Architecture of ANN with 4-10-2 topology.

between experimental and predicted values from ANN were used to evaluate the performance of the proposed ANN in prediction technique. The mean absolute relative errors for the second ANN were: $1.66 \%$ for torque and $0.78 \%$ for thrust force for testing dataset. These levels of error are satisfactory and smaller than errors that normally arise due to experimental variation and instrumenttation accuracy.
Figure 10 shows the comparison between experimental torque and thrust force values and corresponding ANNs outputs for the total dataset (training, validation and testing). These figures show that the significant portion of points clusters along the diagonal line, which in turn is a good indication of performance of training algorithm. The correlation coefficients $\left(\mathrm{R}^{2}\right)$ between experimental and predicted outputs—-values exceed 0.99 for all training, testing and validating datasets. These values show the accuracy of prediction ability obtained from ANN.

\subsection{Comparison between MRA and ANN Prediction Models}

A visual comparison was established between the fitted and experimental values (Figures 11 and 12) for testing and validation datasets of ANN, respectively. Both figures show that the predicted values from ANN approximate the experimental values much more than the

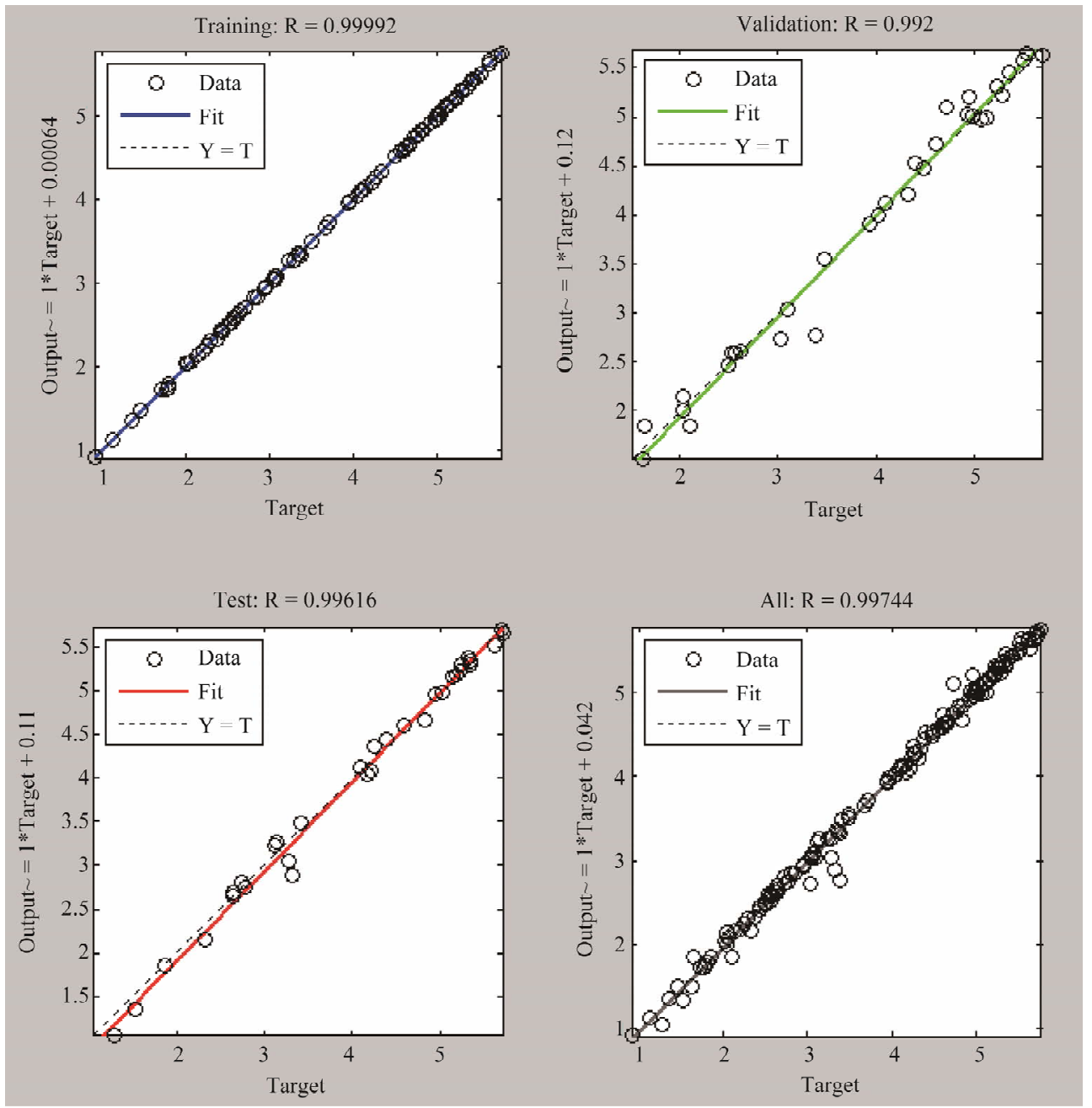

Figure 10. Comparisons between experimental thrust force values and corresponding ANN outputs (4-10-2 structure). 
Table 7. Summary of ANN parameters.

\begin{tabular}{ll}
\hline Neural network parameters & \\
\hline Network type & $\begin{array}{l}\text { Feed forward BP (Levenberg- } \\
\text { Marquardt training algorithm) }\end{array}$ \\
Network architecture & $4-10-2$ \\
Number of hidden layer & 1 \\
Number of hidden neuron & One hidden layer: 10 \\
Transfer function & Sigmoid: input- hidden layer); \\
Number of training examples & 57 \\
Number of testing examples & 12 \\
Number of validating examples & 12 \\
Learning rate & 0.03 \\
Momentum factor & 0.9 \\
Number of epochs & 106 \\
Mean squared error (MSE) & 0.00182 \\
\hline
\end{tabular}

MRA model does. This was also proved by getting smaller absolute relative errors. Experimental value columns in Figures 11 and 12 represent the actual values with $\pm 10 \%$. When compared to the experimental values with predicted values, it can be seen that ANN outputs lie in good prediction ranges compare to MRA outputs.

Now, which prediction method is better and when should each one be used to predict and optimize the drilling process in this situation? In the case of developing empirical relations, MRA model is preferred over ANN model because it is an explicit model while the ANN model is a black box. In the other direction, when data are sparse or not generated from designed experiments, MRA may not be able to produce a better model than ANN; then the ANN modeling method and its associated model may be preferred to the MRA method and its model if such a model is available.

\section{Conclusions}

Two modeling techniques were used to predict the thrust force and torque, namely multiple regression analysis (MRA) and artificial neural network (ANN). Modeling the drilling process using MRA and ANN approach provides a systematic and effective methodology for the prediction. Both MRA and ANN revealed that reinforcement fractions were the important factors that influence the responses (i.e. thrust force and torque) followed by the cutting feed rate. However, spindle speed seemed insignificant in both models.

Many ANN architectures have been used to model the collected experimental data. The best neural network configuration was (4-10-2) which was trained using 57 training examples, tested using 12 examples and validated using 12 examples.

The results of ANN models showed close matching

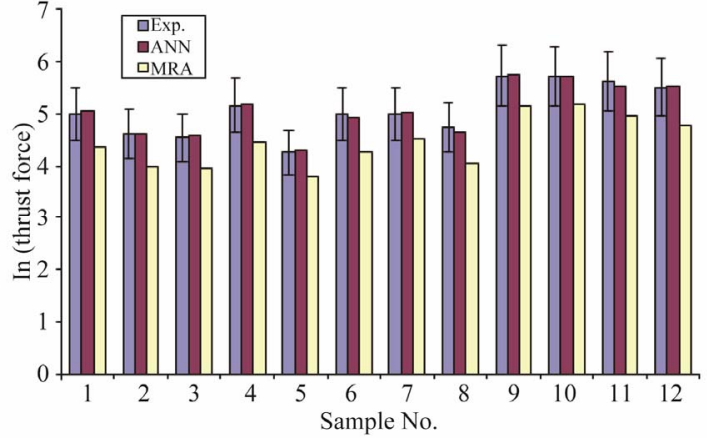

(a)

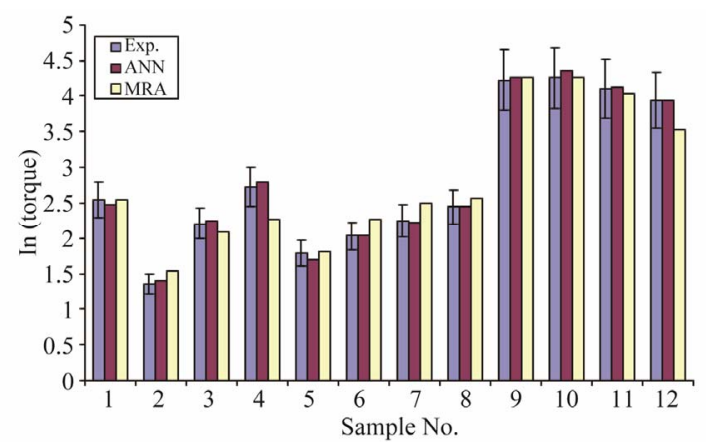

(b)

Figure 11. Experimental vs. predicted values from ANN and MRA for testing dataset: (a) thrust force; and (b) torque.

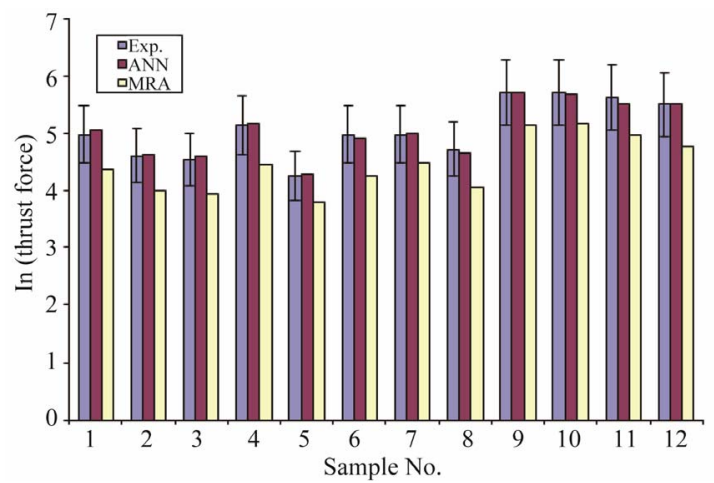

(a)

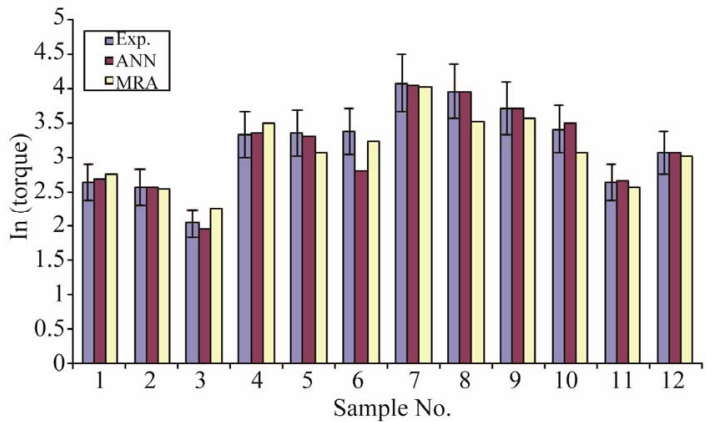

(b)

Figure 12. Experimental vs. predicted values from ANN and MRA for validation dataset: (a) thrust force; and (b) torque. 
between the model outputs and the measured outputs. The mean absolute relative errors were $0.82 \%$ for torque and $2.89 \%$ for thrust force models, while MRA model error values were $7.10 \%$ and $12.59 \%$, respectively. Hence, these models can be used efficiently for prediction potentials for non-experimental patterns which, in turn, save experimental time and cost. It was shown that ANN performs well in mapping nonlinear relationships between inputs and outputs. If both MRA and ANN models are considered they will provide statistically satisfactory prediction results. ANN methodology consumes less time and gives higher accuracy. Hence, modeling the drilling process using ANN is more effective compared with MRA. The two proposed models are good in modeling and predicting the drilling forces, which in turn can provide a valuable tool for many similar applications of modeling methods in engineering design and manufacturing. The developed modeling methods in this paper can aid the prediction, optimization, and improvement of drilling processes and the selection of cutting parameters in the case of drilling aluminum-based materials.

\section{REFERENCES}

[1] J. P. Davim. "Study of Drilling Metal-Matrix Composites Based on the Taguchi Techniques," Journal of materials processing technology, Vol. 132, No. 1-3, 2003, pp. 250254. doi:10.1016/S0924-0136(02)00935-4

[2] N. Altinkok and R. Koker. "Use of Artificial Neural Network for Prediction of Physical Properties and Tensile Strengths in Particle Reinforced Aluminum Matrix Composites," Journal of Materials Science, Vol. 40, No. 7, 2005, pp. 1767-1770. doi:10.1007/s10853-005-0689-5

[3] N. Altinkok and R. Koker, "Modeling of the Prediction of Tensile and Density Properties in Particle Reinforced Metal Matrix Composites by Using Neural Networks," Materials \& Design, Vol. 27, No. 8, 2006, pp. 625-631. doi:10.1016/j.matdes.2005.01.005

[4] A. M. Hassan, M. Hayajneh and M. Al-Omari, "The Effect of the Increase in Graphite Volumetric Percentage on the Strength and Hardness of Al-4wt $\% \mathrm{Mg}$ Graphite Composites," Journal of Materials Engineering and Performance, Vol. 11, No. 3, 2002, pp. 250-255. doi:10.1361/105994902770344024

[5] A. M. Hassan, A. Alrashdan, M. T. Hayajneh, A. T. Mayyas, "Prediction of Density, Porosity and Hardness in Aluminum-Copper-Based Composite Materials Using Artificial Neural Network," Journal of materials processing technology, Vol. 209, No. 2, 2009, pp. 894-899. doi:10.1016/j.jmatprotec.2008.02.066

[6] S. Kalpakjian and S. R. Schmid, "Manufacturing Engineering and Technology," 4th Edition, Addison-Wesley, Boston, 2000.

[7] M. Ramulu, P. N. Rao and H. Kao, "Drilling of $\left(\mathrm{Al}_{2} \mathrm{O}_{3}\right)_{\mathrm{p}} / 6061$ Metal Matrix Composites," Journal of materials processing technology, Vol. 124, No. 1-2, 2002, pp. 244-254. doi:10.1016/S0924-0136(02)00176-0
[8] J. F. Kelly and M. G. Cotterell, "Minimal Lubrication Machining of Aluminum Alloys," Journal of Materials Processing Technology, Vol. 120, No. 1-3, 2002, pp. $327-$ 334. doi:10.1016/S0924-0136(01)01126-8

[9] M. Tash, F. H. Samuel, F. Mucciardi, H. W Doty and S. Valtierra, "Effect of Metallurgical Parameters on the Hardness and Microstructural Characterization of As-Cast and Heat-Treated 356 and 319 Aluminum Alloys," Materials Science and Engineering: A, Vol. 443, No. 1-2, 2007, pp. 185-201. doi:10.1016/i.msea.2006.08.054

[10] M. Nouari, G. List, F. Girot and D. Coupard, "Experimental Analysis and Optimisation of Tool Wear in Dry Machining of Aluminium Alloys," Wear, Vol. 255, No. 7-12, 2003, pp. 1359-1368. doi:10.1016/S0043-1648(03)00105-4

[11] G. Tosun and M. Muratoglu, "The Drilling of $\mathrm{Al} / \mathrm{SiCp}$ Metal-Matrix Composites. Part II: Workpiece Surface Integrity," Composites Science and Technology, Vol. 64, No. 10-11, 2004, pp. 1413-1418. doi:10.1016/j.compscitech.2003.07.007

[12] G. Tosun and M. Muratoglu, "The Drilling of an $\mathrm{Al} / \mathrm{SiC}_{\mathrm{P}}$ Metal-Matrix Composites. Part I: Microstructure," Composites Science and Technology, Vol. 64, No. 2, 2004, pp. 299-308. doi:10.1016/S0266-3538(03)00290-2

[13] J. T. Lin, D. Bharracharyya and V. Kecman, "Multiple Regression and Neural Networks Analysis in Composite Machining," Composite Science and Technology, Vol. 63, No. 3-4, 2003, pp. 539-548. doi:10.1016/S0266-3538(02)00232-4

[14] M. T. Hayajneh, A. M. Hassan, A. Alrashdan and A. T. Mayyas, "Prediction of Tribological Behavior of Aluminum-Copper Based Composite Using Artificial Neural Network," Journal of Alloys and Compounds 2009, Vol. 470, No. 1-2, 2009, pp. 584-588. doi:10.1016/j.jallcom.2008.03.035

[15] S. Frouzan and A. Akbarzadeh, "Prediction of Effect of Thermo-Mechanical Parameters on Mechanical Properties and Anisotropy of Aluminum Alloy AA3004 Using Artificial Neural Network," Materials \& Design, Vol. 28, No. 5, 2007, pp. 1678-1684. doi:10.1016/j.jallcom.2008.03.035

[16] K.Genel, S. C. Kurnaz and M. Durman, "Modeling of Tribological Properties of Alumina Fiber Reinforced Zinc-Aluminum Composites Using Artificial Neural Network," Materials Science and Engineering: A, Vol. 363, No. 1-2, 2003, pp. 203-210. doi:10.1016/S0921-5093(03)00623-3

[17] D. Montgomery and G. C. Runger, "Applied Statistics and Probability for Engineers," John Wiley and Sons, New York, 2003.

[18] M. Negnevitsky, "Artificial Intelligence," 2nd Edition, Addison-Wesley, Boston, 2005.

[19] J. R. Rogier and M. W. Geatz, "Data Mining: A Tutorial-Based Primer," Addison-Wesley, Boston, 2003.

[20] Z. Zhang, K. Friedrich and K. Velten, "Prediction on Tribological Properties of Short Fiber Composites Using Artificial Neural Networks," Wear, Vol. 252, No. 7-8, 2002, pp. 668-675. doi:10.1016/S0043-1648(02)00023-6

[21] S. Kumanan, S. K. N. Saheb and C. P. Jesuthanam, "Pre- 
diction of Machining Forces Using Neural Networks Trained by a Genetic Algorithm," Institution of Engineers Journal, Vol. 87, No. 3, 2006, pp. 11-15.

[22] M. M. Hamasha, A. T. Mayyas, A. M. Hassan and M. T. Hayajneh, "The Effect of Time, Percent of Copper and Nickel on Naturally Aged Al-CuNi Cast Alloys," Journal of Minerals \& Materials Characterization \& Engineering, Vol. 11, No. 2, 2012, pp. 117-131.

[23] A. T. Mayyas, M. M. Hamasha, A. Alrashdan, A. M. Hassan and M. T. Hayajneh, "Effect of Copper and Sili- con Carbide Content on the Corrosion Resistance of Al-Mg Alloys in Acidic and Alkaline Solutions," Journal of Minerals \& Materials Characterization \& Engineering, Vol. 11, No. 4, 2012, pp. 435-452.

[24] M. M. Hamasha, A. T. Mayyas, A. M. Hassan and M. T. Hayajneh, "The Effect of Time, Percent of Copper and Nickel on the Natural Precipitation Hardness of Al-Cu-Ni Powder Metallurgy Alloys Using Design of Experiments," Journal of Minerals \& Materials Characterization \& Engineering, Vol. 10, No. 6, 2011, pp. 479-492. 